\title{
APPLICATION OF COMPLEX-ALLOYED POWDERS PRODUCED BY THERMOCENTRIFUGAL SPUTTERING IN FLUX-CORED WIRES
}

\author{
A.P. ZHUDRA, S.Yu. KRIVCHIKOV and V.I. DZYKOVICH \\ E.O. Paton Electric Welding Institute, NASU \\ 11 Bozhenko Str., 03680, Kiev, Ukraine. E-mail: office@paton.kiev.ua
}

\begin{abstract}
This paper presents the results of evaluation of the influence of complex-alloyed powders (CAP) on welding-technological properties of flux-cored wires and deposited metal performance. Possibility of ensuring a high degree of flux-cored wire alloying at reduction of its diameter is considered. Tribotechnical characteristics of metal deposited with flux-cored wires are determined at CAP application as a filler. The paper presents the results of metallographic investigations of deposited metal. It is established that CAP application as flux-cored wire core is favourable for the mode of electrode metal melting and transfer leading to improvement of their welding-technological characteristics. Wear resistance studies of deposited metal showed an improvement of wear resistance of deposited metal operating under the conditions of abrasive wear and metal-over-metal friction. 4 Ref.. 5 Tables. 3 Figures.
\end{abstract}

$\boldsymbol{K} \boldsymbol{e} \boldsymbol{y} \boldsymbol{w} \boldsymbol{o r d} \boldsymbol{s}:$ flux-cored wire, thermocentrifugal sputtering of ingots, complex-alloyed powders, welding-technological characteristics of flux-cored wire, tribotechnical characteristics of deposited metal

Flux-cored wires produced to GOST 26101-84 have a core, in which the alloying part consists of crushed ferroalloys and metal powders. Ensuring a high degree of alloying, usually, necessitates application of high $(40-50 \%)$ values of the filling coefficient. This, in its turn, leads to increase of flux-cored wire diameter up to $3.2 \mathrm{~mm}$ and more. Stable process of surfacing with such flux-cored wire requires considerable current (400-500 A) and arc voltage $(28-32 \mathrm{~V})$, that is not rational or inadmissible for some types of parts being reconditioned, which are sensitive to high temperature impact, prone to thermal deformation, etc. (in such cases application of largediameter flux-cored wires leads to considerable power consumption). Thus, solution of the problem of flux-cored wire diameter reduction at preservation of its required alloying level, is of considerable practical interest.

PWI developed the technology of producing complex-alloyed powders (CAP), which consists in melting out an ingot of cylindrical form of the required composition from a mixture of ferroalloys and other alloying materials, and its subsequent plasma-arc centrifugal sputtering in the modes, ensuring production of spherical powder particles of the required granulometric composition. The composition of each particle should correspond to calculated composition of surfacing

(c) A.P. ZHUDRA, S.Yu. KRIVCHIKOV and V.I. DZYKOVICH, 2014 electrode materials, namely flux-cored wires, strips, filler rods, stick electrodes , etc.

In addition, spherical shape of CAP particles (Figure 1,b), unlike irregular-shaped particles (Figure 1, $a$ ), will ensure a more dense filling of the core and will enable reducing flux-cored wire diameter.

On the other hand, replacement of mechanical mixture of core materials of nonuniform structure, properties and chemical composition by CAP, will result in changes of core electric and thermophysical properties. This, in its turn, will influence the welding-technological properties of flux-cored wire and, possibly, deposited metal characteristics.

The objective of this work is experimental investigation of CAP influence on welding-technological characteristics of flux-cored wires and wear resistance of deposited metal. Earlier [1] PWI performed investigations on application of granulated alloy of the respective composition as the core of PP-Np-25Kh5FMS flux-cored wire. This study focused on improvement of deposited metal high-temperature resistance.

As objects of study, we selected two fluxcored wires of another type: PP-AN170 (PP-Np80Kh20R3T), applied for hardfacing of parts operating under the conditions of intensive abrasive and hydroabrasive wear (teeth of excavator ladles, dredge noses, etc), and PP-AN160 (PP-Np200KhGR) used for hardfacing of parts operating under the conditions of lubricated friction of metal over metal (cast iron crankshafts of car engines). 
Table 3. Chemical composition of deposited metal, wt.\%

\begin{tabular}{||c|c|c|c|c|c|c|c|}
\hline $\begin{array}{c}\text { Flux-cored wire } \\
\text { type }\end{array}$ & $\mathrm{C}$ & $\mathrm{Cr}$ & $\mathrm{Si}$ & $\mathrm{Mn}$ & $\mathrm{Ti}$ & $\mathrm{Al}$ & $\mathrm{B}$ \\
\hline PP-AN160 & 2.2 & 0.3 & 1.2 & 0.8 & 0.3 & 0.2 & 0.08 \\
\hline PP-AN160SF & 2.0 & 0.5 & 0.8 & 0.6 & 0.3 & 0.1 & 0.1 \\
\hline PP-AN170 & 1.1 & 18.5 & 0.7 & 0.8 & 0.3 & - & 2.6 \\
\hline PP-AN170SF & 0.9 & 19.1 & 0.5 & 0.8 & 0.4 & - & 2.9 \\
\hline
\end{tabular}

Abrasive wear-resistance testing of metal deposited with PP-AN170 and PP-AN170SF fluxcored wires was conducted in NKM friction machine by «stationary ring» schematic at friction against non-fixed abrasive [3]. Test samples of $16 \times 16 \times 6 \mathrm{~mm}$ size were cut out of the third or fourth layer of multilayer deposit, produced in the above mode. Deposited metal composition is given in Table 3. Relative wear resistance was assessed as the ratio of the loss of reference-sample mass (metal deposited with flux-cored wire PP-AN170) to loss of mass of the sample, deposited with PP-AN170SF flux-cored wire. Derived results are given in Table 4 .

Test results indicate that CAP application as the core of PP-AN170 flux-cored wire leads to increase of deposited metal abrasive wear resistance by $22-23 \%$. Comparative metallographic analysis of deposited metal structures (Figure 2) showed that CAP does not have any influence

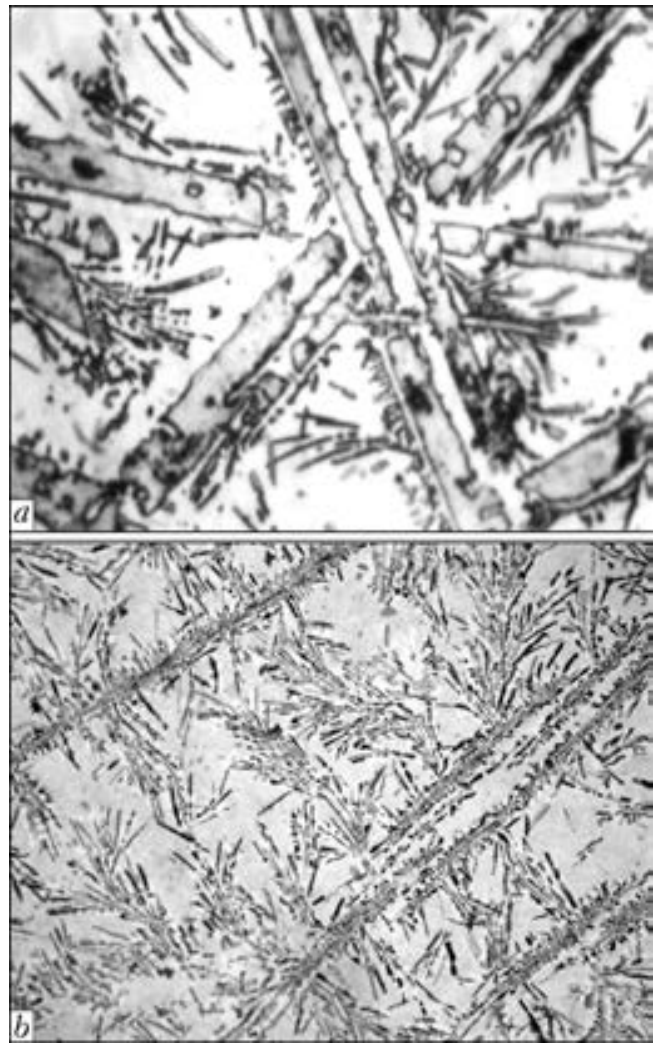

Figure 2. Structure $(\times 500)$ of metal deposited with fluxcored wires PP-AN170 $(a)$ and PP-AN170SF $(b)$
Table 4. Results of abrasive wear resistance testing of metal deposited with PP-AN170 and PP-AN170SF flux-cored wires

\begin{tabular}{||c|c|c|c|c||}
\hline \multirow{2}{*}{$\begin{array}{c}\text { Sample } \\
\text { grade }\end{array}$} & \multicolumn{2}{|c|}{ Sample mass, g } & \multirow{2}{*}{ Wear, g } & $\begin{array}{c}\text { Relative } \\
\text { wear } \\
\text { resistance }\end{array}$ \\
\cline { 2 - 5 } & Before testing & After testing & & 1 \\
\hline $170-1$ & 12.0436 & 11.9017 & 0.1419 & 1.27 \\
\hline 170 SF-1 & 12.0003 & 11.8888 & 0.1115 & 1 \\
\hline $170-2$ & 12.4266 & 12.2736 & 0.1530 & 1.22 \\
\hline 170 SF-2 & 11.6245 & 11.4991 & 0.1254 & 1 \\
\hline $170-3$ & 12.1111 & 11.9717 & 0.1394 & 1.32 \\
\hline 170 SF-3 & 12.2234 & 12.1176 & 0.1058 & \\
\hline
\end{tabular}

on composition, but changes the degree of dispersity and hardness of structural components.

So, metal deposited with PP-AN170SF fluxcored wire (Figure 2, $b$ ) is characterized by formation of carboborides and eutectic with higher degree of dispersity than for metal deposited with PP-AN170 flux-cored wire (Figure 2, $a$ ). Both in the first and in the second case hardness of carboborides and eutectic is practically the same, and is equal to $H V 1-14000-17000$ and $H V 1-$ 9200-14500, respectively. At the same time, hardness of the matrix of metal deposited with PP-AN170CF flux-cored wire is higher and is equal to $H V 1-7200-8600$, whereas for metal deposited with AN170 flux-cored wire it is $H V 1$ 6500-7400. In all probability, higher hardness of deposited metal matrix is also responsible for its higher abrasive wear resistance.

Determination of tribotechnical parameters of metals deposited with PP-AN160 and PPAN160SF flux-cored wires was conducted in friction machine SMT-1 by roller-block method to GOST 23224-86. Blocks were segments of standard car inserts AO 20-1. Blanks of VCh50-2 cast iron were used for roller production. Their cylindrical surface was surfaced with test fluxcored wires in the above modes, and then ground to nominal dimensions: $12 \mathrm{~mm}$ thickness and $50 \mathrm{~mm}$ diameter. Composition of tested deposited metals is given in Table 3.

Testing of friction-sliding pairs with lubrication was performed in two stages: in running-in mode and at working load. Value of optimum working load $P_{\text {op }}$ was selected on the basis of preliminary experiments, which showed that its increase can lead to «seizure» on deposited metal-insert mating surface. Total wear rate $I_{\Sigma}$ on the whole was determined as a sum of intensities of wearing of insert $I_{\mathrm{b}}$ and roller $I_{\mathrm{r}}$. Procedure of determination of these values is given in GOST 23.224-86. In addition, during testing the change of the coefficient of mating surface friction $f_{\text {fr }}$ 
Table 5. Tribotechnical characteristics of friction-sliding pairs

\begin{tabular}{|c|c|c|c|c|c|c|c|}
\hline \multirow{2}{*}{$\begin{array}{l}\text { Mating surface } \\
\text { number }\end{array}$} & \multirow{2}{*}{$\begin{array}{l}\text { Type of mating surface and } \\
\text { flux-cored wire }\end{array}$} & \multicolumn{2}{|c|}{ Performance characteristics } & \multicolumn{3}{|c|}{ Wear rate, $\mathrm{mm} / \mathrm{m} \cdot 10^{-4}$} & \multirow{2}{*}{$f_{\mathrm{fr}} \cdot 10^{-2}$} \\
\hline & & $P_{\mathrm{op}}, \mathrm{MPa}$ & $T_{\text {fr }},{ }^{\circ} \mathrm{C}$ & $I_{\mathrm{r}}$ & $I_{\mathrm{b}}$ & $I_{\Sigma}$ & \\
\hline 1 & $\begin{array}{l}\text { Deposited metal-insert. } \\
\text { PP-AN160 flux-cored wire }\end{array}$ & 11 & 72 & 0.24 & 0.26 & 0.5 & 45 \\
\hline 2 & $\begin{array}{l}\text { Deposited metal-insert. } \\
\text { PP-AN160SF flux-cored wire }\end{array}$ & 14 & 50 & 0.22 & 0.12 & 0.34 & 20 \\
\hline
\end{tabular}

and temperature of frictional heating of oil $T_{\mathrm{fr}}$ was recorded.

Obtained data (Table 5) show that wear resistance of deposited metal of mating surfaces 1 and 2 is approximately the same. At the same time $I_{\Sigma}$ of mating surface 2 is 1.5 times lower than that of mating surface 1 , that is due to smaller $I_{b}$ value of mating surface 2 . Proceeding from that it can be stated that for the two compared mating surfaces application of PPAN160SF flux-cored wire provides deposited metal with higher antifriction properties.

Metallographic examination of deposited metal of mating surfaces 1 and 2 was conducted to detect the causes affecting the derived results. It should be noted that detailed analysis of structural-phase state of the multicomponent alloy, which solidified under non-equilibrium conditions, is a rather labour-consuming task. However, it can be stated with sufficient degree of validity that the deposited metal structure (at application of both PP-AN160 and PP-AN160SF flux-cored wire) consists of two main phases: austenite decomposition products (pearlite + residual austenite) and carbide-cementite phase (Figure 3). The latter has the form of ramified reinforcing net with regions of different thickness in the section plane.

In the micrograph this phase is of white colour, and pearlite-austenite phase is black that allowed assessment of their quantitative ratio. As a result, it was established that deposited metal of mating surface 1 contains $40-46 \%$ of «white» (carbidecementite) phase of hardness $H V-0.58000-8200$. Hardness of solid solution grains is $H V 0.5-5000-$ 5200. In the deposited metal of mating surface 2 the fraction of carbide-cementite phase is 28$33 \%$, and its hardness remains to be the same as in the deposited metal of mating surface 1. At the same time, pearlite hardness in deposited metal of mating surface 2 ( $H V-0.5-5800-6200)$ is significantly higher than that of deposited metal of mating surface 1.

Thus, it can be stated that reduction of the fraction of hard carbide phase in the deposited metal, which is also abrasive relative to the insert, promotes lowering of wear rate of the insert and mating surface as a whole. At the same time, reduction of the quantity of wear-resistant structural component is compensated by increase of solid solution hardness and quantity. As a result, wear rates of deposited metal of mating surfaces 1 and 2 remain approximately the same. Metallographic analysis could not reveal the mechanism of CAP influence on quantitative ratio of phases in the deposited metal and their hardness. It can be assumed, however, that this is related to influence of boron as an active modifying and carbide-forming element.

In [4] it is shown that the form of boron-containing material $\left(\mathrm{B}_{4} \mathrm{C}, \mathrm{B}_{2} \mathrm{O}_{3}, \mathrm{BN}\right.$, etc. $)$ in the

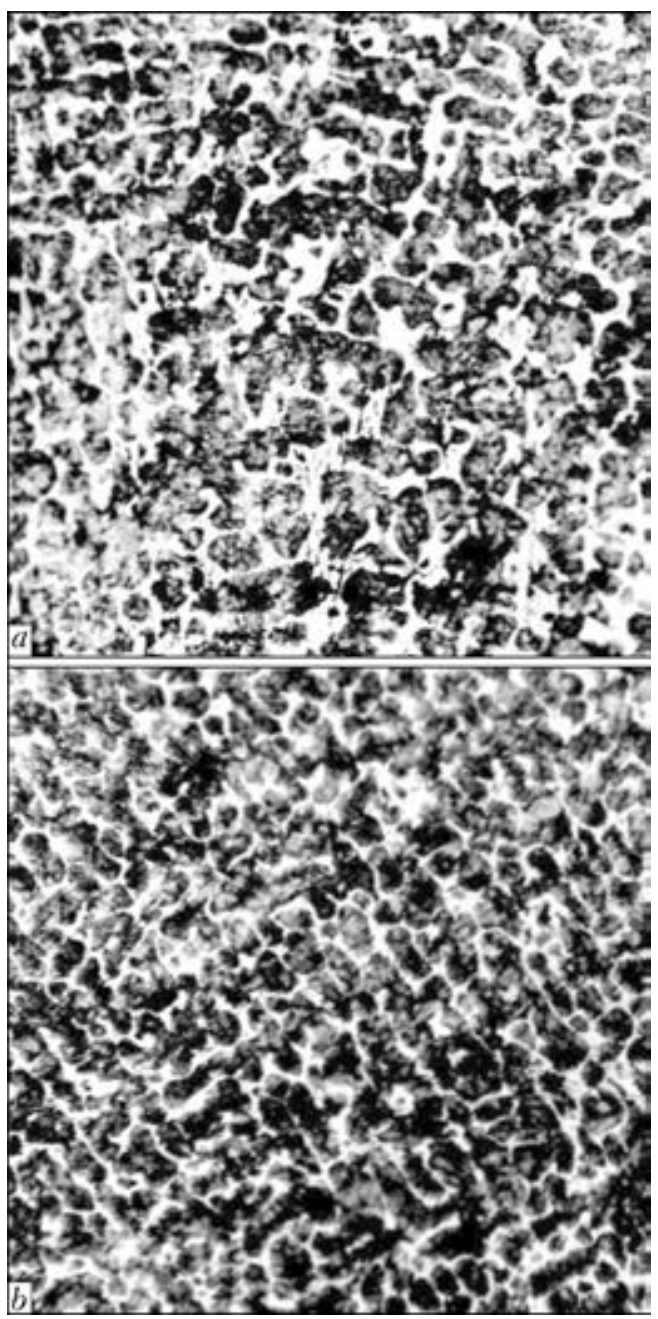

Figure 3. Structure $(\times 320)$ of metal deposited with fluxcored wire PP-AN160 $(a)$ and PP-AN160SF $(b)$ 
composition of flux-cored wire core has an essential influence on their quantitative ratio and morphology of deposited metal phase components. Even though boron was added to the composition of PP-AN160 and PP-AN160SF flux-cored wire cores in the same amounts, but different boroncontaining materials were used: in the first case - iron-chromium-boron master alloy, and in the second case - CAP particles. It is also possible that different content of carbide-cementite phase in the studied samples of deposited metal is the result of varying carbide-forming activity of boron, depending on its compositional state.

\section{Conclusions}

1. Application of complex-alloyed powders as core of complex-alloyed flux-cored wires allows an essential reduction of its diameter without changing the alloying level, reduction of power consumption in surfacing processes and improvement of deposited metal performance. Replacement of core of PP-AN170 flux-cored wire by CAP core allowed improvement of its weldingtechnological characteristics, reducing its diameter from 3.2 to $2.6 \mathrm{~mm}$ and increasing abrasive wear resistance of deposited metal by $1.2-1.3$ times.
2. Replacement of mechanical mixture of charge materials of non-uniform composition in flux-cored wire core by CAP influences the quantitative composition and hardness of deposited metal structural components. CAP application in PP-AN160 flux-cored wire reduces the fraction of abrasive carbide phase and increases the hardness of deposited metal pearlite base that increases by 1.3 times the wear resistance of mating surface exposed to metal-over-metal friction in service.

1. Kondratiev, I.A. (1980) Flux-cored wire filled by granular alloy. In: Theoretical and technological principles of surfacing. Surfacing of metallurgical and power engineering parts. Kiev: PWI.

2. Dzykovich, V.I. (2010) Study and development of materials for wear-resistant surfacing based on spheroidized granules of tungsten carbides: Syn. of Thesis for Cand. of Techn. Sci. Degree. Kiev.

3. Yuzvenko, Yu.A., Gavrish, V.A., Marienko, V.Yu. (1979) Laboratory units for evaluation of wear resistance of deposited metal. In: Theoretical and technological principles of surfacing. Properties and tests of deposited metal. Kiev: PWI.

4. Zhudra, A.P., Krivchikov, S.Yu., Petrov, V.V. (2004) Selection of boron-containing charge materials for the core of flux-cored wire. The Paton Welding $J ., 4,51-52$.

Received 22.09.2014 